expected, in fibrous union. The choice would therefore seem to lie between a mandible firmly united, capable of bearing the strain of an efficient denture, or the teeth in

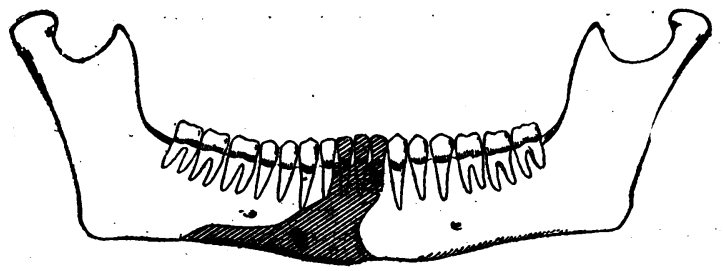

Frg, 5.-Loss of tissue indieated by the darkened area.

correct occlusion on a base not capable of bearing the strain of mastication.

In the incisor region the fragments are allowed to approximate, provided the narrowing does not lead to marked deformity of the face and disorganization of the occlusion. An examp!c may be quoted:

CASE vi.

The bullet carried away the bone, as shown in Fig. 5 . The parts were approximated and osseous union followed with but slight interference with the occlnsion of the with the occlusion of

In the premolar region, and especially the molar

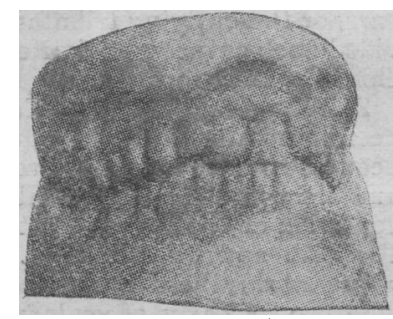

FIG. 6. region, the following method is adopted: 'The upper teeth opposing the teeth of the posterior fragment are removed; this allows the posterior fragment to spring forwards and upwards, the anterior fragment being allowed to swing over to the injured side. In practice the following method is pursued:

Where the gap is small, the posterior fragment is released, and a splint made with the anterior fragment in position. Skiagrams are then obtained. If the bony parts are seen to be in contact, the splint is fixed in position; otherwise the anterior fragment is brought across until contact is obtained. The mandible is, therefore, in many cases mended with the anterior fragment swung over to the injured side. 'I'his is no disadvantage, because, with the removal of the splint, the mandiblo tends to readjust itself to functional actirity, provided the so-called "bite of comfort" is avoided. "This condition requires a word of explanation. In-fractures about the region of the angle the ramus moves forwarts and brings the soft tissues in contact with the upper teeth, but even if there is no loss of tissue, the soft tissues aire considerably damaged, and when licaling is complete there is a certain amount of permanent swelling, and a similar condition follows. The result is that tho patient, in ovder to obtain a " bite of comfort," involuntarily brings the mandible over to the injured side, and the teeth are not in occlusion; further, in many cases definite ulecration of the soft tissue follows.

It is difficult to say what is the breadth of gap that can be satisfactorily reduced in this manner without causing undue deformity, but it probably varies in in. dividual cases. Good lesults may be confidently anticipated where the gap is less than three-quarters of an inch, and even with gaps up to one inch approximation may prove successful in some cases. With a wider gap, approximation of the fragments must give way to bone grafts for the formation of an osscous bridge.

The following case may be quoted because it illustrates in an excellent manner: (1) The effects of the glancing. shot on the bone; (2) the approximation of the fragments to obtain union; (3) fixation in a malposition; (4) re\&djustment of the mandible to functional activity.

\section{CASE VIr.}

The patient was injured on August 18th, 1916, and admitted September 14th. The bullet entered one inch behind the left angle of the mandible, and emerged through the right side of the bone, about midway between the angle and the symphysis; and about midway between the lower border of the bone and

the alveolav border.

On admission there was a sinus at the site of the exit wound; there was a purnlent discharge, and a probe passed up the sinus on to bare bone. The teeth present were:

$$
\begin{array}{l|l|l}
7654321 & 1234567 \\
\hline 7654521 & 1234567
\end{array}
$$

The mouth was gagged open on the secoud molars. The skiagram showed loss of bone in the region of the first molar and a comminution of the bone extending. backwards to the second molar and forwards to the incisors. The following teeth were removed:

$$
\begin{array}{l|l|}
876 & \\
876543 & \\
& *
\end{array}
$$

The sinus was dilated; and a few fragments of necrosed bone were removed. The patient was then left to allow the fragments to approximate by natural means. The left fragment passed across to the right, and the right or posterior fragment swung forwards. A splint was adjusted to bring the left fragment still further to the right; this was fixed on October 5th, ment still further to the right; this was fixed on October 5 th,
and by the end of Jautary there was good union. At this period the teeth on the left side were not in occlusion, but the efforts of the patient to titilize the teeth soon resulted in these teeth assuming the correot occlusion.

\section{Fixation of the Fragments.}

Many splints have been devised for the treatment of the fractured mandible. The most self-cleansing and the most reliable is the metal Gunning splint fixed in position with oxyphosphate of copper. Hooks, elastic bands, and wires only add to the difficulty of cleansing the mouth.

In conclusion, it may be said with confidence that if ordinary surgical principles arc adopted in the treatment of gunshot injuries of the mandible, the most excellent results can be expected. 'To adapt splints in a "field of sepsis," as is so often done, is to ignore the most elementary surgical teaching.

A detailed account, fully illustrated, of the methods referred to in this paper was published in the British Dental Journal, March 15th, April 2ud, and April 16th, 1917.

\section{THE DEPAR'TMEN'T OF ORAL SURGERY OF THE HARVARD SURGICAL UNIT. \\ BY \\ MAJOR V. H. KASANJIAN.}

During the present war soldiers who have received wound of the face and jaws have for the first time been collected in centres for treaturent. This concentration has made if possible to systematize and simplify certain phases of the work and to form definite conclusions as to the cause and treatment of certain complicatious.

Some of the advantages havo been :

The nursing staff is more efficient as they become familiar with and devote their entire atbention to the care of fractured jaws. The daily care and feedling bave been organized to makê easier the treatment of a large number of patients.

'The development of a mechanical laboratory has made it possible to apply at an early date the splints and appliances twich antial to successful treatment

Thie treatment of cases durin: a period of over eighteen months has given opportunity to maintain a comprehensive system of records from which deductions can be made on the complications, mortality, etc.

\section{Daily Care of the Palient.}

Cases are admitted to the department usually from two to threc days after injury. They are suffering from mental shock, toxic absorytion frow the-wounds, and from lack of nourishment owing to the inflammation of the soft tissues and the derangement of the organs of mastication.

The mouth is imigated at frequent intervals during the day and night, in most cases overy two hours, and in addition the mucous surfaces are swabbed with cotton pledgets saturated in tincture of iodine or hydrogen per: oxide, to remore mechanically mucous deposits and adherent food particles.

The majority of operations are performed under a local anaesthetic. 'This procedure makes it possible to remove foreign bodies, fragments of teeth or roots, and detached segments of bone. The suppuration or becrosis during the early stages of treatment is thus materially reduced. 
Immobilization of the Maxillary Bones.

We believe that early immobilization of maxillary fractures means the quickest and most satisfactory recovery. While technical difficulties may stand in the way, since nearly every splint must be made to suit each individual case, we have devoted considerable attention to the classification of the type of splints, and the simplification of their preparation. A number of devices of a simple and temporary nature have been designed to immobilize the jaws during severe illness, and until mole permanent splints can be employed.

For cases of ordinary severity, the usual splints (with or without modifications) familiar to the oral surgeon are used. In many cases of extensive destruction of hard and soft tissues it was found that.intraoral splints were inadequate, and an external support, consisting of a series of valcanite plates fitted orer the forehead, with a headgear of straps, was developed. With this appliance as a base, the tissues of the mouth, nose, eyes, and neck are under control, either during the process of scar contraction or after plastic operations.

In the many cases of extensive loss of the mandible accompanied by laceration of the lower part of the face and neck; a sectional or folding artificial jaw has been successfully used; it acts as a framework for plastic operations, is easily removed, and at the same time maintains the contour of the lower part of tlie face.

In restoring the upper jaw, a satisfactory means of retention and also of resistance to the force of mastication has been desioned, and in cases in which the loss of the mandible has been sufficiently extensive to destroy the function of the temporo-mandibular joint, a mechanical condyle has been substituted.

\section{Septic Complications.}

The special septic complications, apart from the usual condition of local sepsis in the w sund, which have been observed, are septicaemia, cellulitis, and bronchopneumonia. No cases of pyacmia have occurred.

Septicaemia.-There have been two cases of septicaemia, both ending fatally. In each the wounds of entry and exit were small. In one there was a scarlatiniform rash and the infection was thought to be streptococcal, but no blood cultures were made. In the other, growths of a bacillus were obtained from samples of blood taken on two successive days. The bacillus was not identified, as it died off in all the subcultures.

Cellulitis.-A form of cellulitis spreading from the wound over the face and scalp has been observed in several instances. It was accompanied by pyrexia, but in no case did the patient seem very ill or suffer from any serious consequences. The affected area of skin has been light pink in colour, slightly tender, with a definite induration at the spreading margin. These cases have been regarded as mild erysipelas, and have been treated as such. In some instances the condition has recurred in the same patient.

Bronchopneumonia.-This has been one of the most fatal complications. Preliminary septic bronchitis has occurred in some cases; in others the onset of pueumonia has been sudden. Empyema and multiple abscesses in the lung have been common, and the mortality has been high. The pulmonary infection seems to be attributable, as a rule, to the inlialation of septic material from the mouth, and a high percentage of the cases has followed general anaesthesia. Many patients were suffering from broncho. pneumonia at the time of their admission, and it was usually found that they had already been operated upon élsewhere under general anaesthesia.

\section{Value of Local Anaesthesia.}

Our practice now is to employ local anaesthesia when ever this is possible for operation upon patients with wounds which communicate with the moutl. If general anaesthesia is necessary, special precautions are taken to prevent the entry of septic material into the air passages. These precautions are as follows:

1. A hypodermic injection of a hundredth of a grain of atropin is given one hour before operation in order to reduce the secretion of saliva.

2. The mouth is carefully cleaned by swabbing and syringing immediately before the operation is commenced.

3. The administration of the ansesthetic is conmenced in the ordinary way. As soon, however, as the patient is unconscious, and before he has lost his reflexes; nasal tubes are passed through the nostrils into the pharyn $x$, and the administration is continued through them while the buccal cavity is well packed with dry gauze, so as to prevent the backward escape of blood and other fluids.

Those who are working at clearing stations and other points where men with gunshot wounds involving the mouth receive treatment before reaching the base should always bear in mind the great danger of giving general anaesthetics to these patients.

\section{Plastic Operations.}

So far as concerus the soft tissues, these may be considered under the following headings:

1. Primary Suture.-There does not appear to be much scope for primary suture of gunshot wounds complicated by fracture of the jaw, for reasons which are manifest. However, so long as general anaesthesia is not employed, some advantage may follow accurate primary suture of those portions of a wound which involve the lip margins, the eyelids, the alae of the nose, portions of the external ears, or the outlying tributaries of a radiating wound, provided such suturing is limited, and no attempt is made to close the entire wound.

2. Secondary Suture.-Early secondary suturing has been increasingly employed of late. The interval that has been allowed to elapse between the infliction of the wound and its complete or partial closure has varied with the condition of local sepsis, but has most often been between the fifth and twelfth days. B.I.P. has been used as an adjuvant in these operations, we think with advantage. The use of early secondary suturing has done much to lessen the amount of deformity from scarring.

3. Flap Operations.-Although primary or early secondary suturing may be practised with success in some cases, yet extensive operations required for reconstruction of the face to cover deficiencies which have been brought about by actual destruction of tissue, or by scarring and laceration, are invariably postponed until all suppuration has disappeared. Primary or early secondary suturing may have served to bring the edges of a lacerated wound into apposition, or suturing may have been done at a later date to extend mucous surfaces or to lessen the deformity as a preparatory measure for an extensive plastic operation. In other words, in the first instance the suturing reduces the size of a wound in which there is no loss of substance, and in the second instance it lessens the area to be covered by flaps. In all cases in which there is an appreciable loss of substance and a plastic operation is contemplated, an appliance to reproduce the bony tissue is always made to serve as a framework, to give a natural contour to the soft tissues of the face or neck, and to prevent undue scar contraction.

Eren for extensive plastic operations local anaesthesia is almost invariably used, because the majority of patients prefer it to a general anaesthetic, whilst from the operator's point of view it is better because he can take his own time to obtain juxtaposition of the flaps, the loss of blood is much less, the patient is quiet and under perfect control, and the dangers of a prolonged operation are reduced to a minimum.

\section{Haemorrhage.}

Among 400 cases of gunshot wound of the face with fracture of the upper or lower jaw treated in this depart. ment there have been 34 cases of secondary haemorrhage (8.5 per cent.), and of these 7 were fatal.

Injury of one or both lingual arteries in the floor of the mouth has been the chief cause of serious bleeding. In the majority of cases it has not been possible to secure the bleeding point, and proximal ligature has been employed. This, however, has not alvays been satisiactory, as it is often impossible to identify with certainty the vessel whicli is bleeding. Efforts to overcome this uncertainty by ligating the external carotid artery were not encouraging. $O$ wing to the dropping of the fractured jaw and other anatomical and pathological derangements, the external carotid is not easy to find and ligate in these cases, the operation is somewhat prolonged and has a high mortality; moreover, concomitant injury of both linguals is not uncommon, in which event ligation of one external carotid is not sufficient. Recently we have had better results by direct ligation of one or both lingual arteries whenever 
the anatomy of the weund was indicative of injury of these vessels.

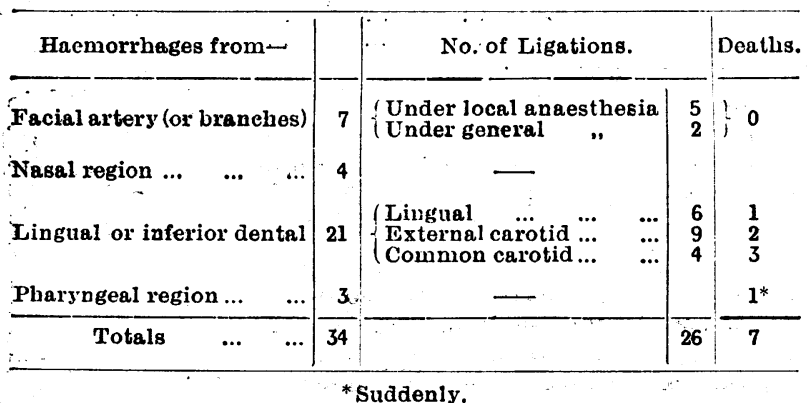

The above figures are compiled from the records of the first 400 cases of gunshot wound of face and jaw treated in the

department.

The tatal of cases of haemorrhage is 34 and not 35 , since one patieut had haemorrbage diatinctly from both the nasal and the pharyngeal regions. One death occurred immediately following haemorrhage from the pharyngeal region before any assistance could be given. One case died from shock within a -few hours gfter ligation of both lingual arteries. of the five rem cerebral embolism. The three fatal cases from ligation of the common caratid had all previously had the external carotid ligated, but owing to a recurence of haemorrhage the former artery was ligated as a last resort.

Mortality.

of 436 recorded cases of injuries to the face and jaws treated in the department between July, 1915, and January, 1917, 19 patients died from the following causes:

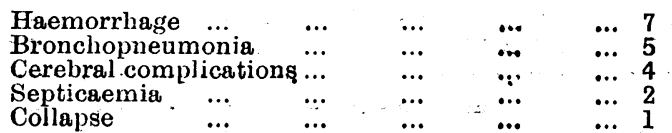

It is hard to malre an accurate analysis of the percentage of deaths among patients suffering from gunshot wound of the face and jaiw, because wounds of other parts of the body may exist which are of more serious consequence than those of the jaw. Of the four cases which died from cerebral complications, three were suffering from fracture of the base of the skull and one from spinal injury in addition to the jaw wounds.

Most of the patients - who succumbed to bronchopneumonia bad contracted this complication previous to admission to the department.

\section{Conclusions.}

We feel that some of the advances liave been:

1. A realization of the importance of immobilization or reduction of maxillary fractures at the first possible mement along the lines of normal occlusion of the teeth.

2. Early reduction of sepsis by small and timely operations with a local anaesthetic.

3. A better understanding of the dangers attending the use of general anaesthetics for operations on patients suffering from face and jaw injuries.

4. The control of severe complications, especially of secondary haemorrhage.

5. The modification and simplification of many types of oral splints.

6. Temporary and permanent oral restorations.

7. The use of local anaesthesia for extensive plastic operations about the face, mouth, and neck.

This summary of the work has not included an appreciable number of cases which have been treated from necessity in other hospitals, nor a large number of patients who have received attention for dental and oral complications.

DR. LUDWIG LAZARUS ZaMEnHoF, the inventor of the international language known as Esperanto, who died recently, was a member of the medical profession. He was born in 1859 at Byalistok, Grodno, in Russia, and practised as an ophthalmic surgeon in Warsaw. Esperanto was presented to the world in 1887:

\section{A NOTE ON ORAL SCRGERY.}

BY

\author{
Major A. C. VALAdIER, C.M.G., R.A.M.C. \\ AND
}

Captain H. LAWSON IVHALE, R.A.M.C.

The advances in the surgery of the jaw and face have been gradual, but as the result of experience a few points have crystallized out with distinctness.

At the beginning of the war brokes fragments of bone were removed too freely; many such if left would have thrown out callus. A tooth should never be removed if there is any chance of it subsequently forming a useful support for dentures or otlier appliances. Even in the line of fracture the extraction of a tooth may be left until later, since for the period immediately following injury it may provide an invaluable point d'appui for some appliauce.

Maxilla.

If the tuberosity carrying a molar tooth be separated from the rest of the bone by fracture, but the muco-peri. osteum is continuous, it should never be removed. "It may be kept in position by any convenient method, whether by splint or by silk stitches through its muco-periosteum; and it will always unite with the parent bone. In the case of transverse fracture through both maxillae (with or without fracture of the palate), producing a downward sag of the maxillae en masse, the whole may be hifted up by a vulcanite plate moulded to the roof of the mouth; from the sides of this plate brass rods fitted with hooks permit of a constant pull by means of bandages fixed over the head. Union is established in less than three weeks. These two statements as to fractures of the maxillae are emphasized as being invariably true.

Mandible.

The displacement of fragments in a complete fracture of a ramus is often obstinate, and suitable neither for wiring nor, if there be a gap, for subsequent bone grafting. Occlusion of teeth in this very frequent type of case is obtained by building up the depressed side with vulcanite or a metal gutter, on which are fixed teeth.

Injury of Facial Nerve.

Often the loss of soft parts lias involved a great part of the facial nerve, and on the injured side the angle of the mouth maintains its original relation to the lower jawthat is, it is depressed. 'The tissue of the cheek is cica. tricial, and anastomosis of the nerve is impracticable. A good result is obfained by elevating the mouth angle by a plastic operation.

Closure of Wounds.

A wound, however fetid, anywhere in the neighbourhood of the jaw ramus, should be closed as soon as possible. For drainage by tube a median stab-wound is then made beneath the chin.

Formation of Flaps.

Where a large gap in the cheek has to be covered by sliding a flap from one oi botli edges of the wound, the large amount of undercutting necessitated tends to impair vitality, and in particular to raise the tension on the stitches. 'To aroid these drawbacks the first third of the undercutting may be of dermis only; the next third may include fat and subcutaneous tissue; and the last thirdthat is to say, the most proximal part of the flap-may also embrace deep fascia. On pulling the flap in the necessary direction its deep surface now becomes shaped like a staircase; the blood supply is cut off to a less extent, and the tension is more diffusely distributed.

General Conclusion.

Speaking generally of facial wounds, it is advisable to delay considerably before doing final and finishing operations, but not at all before the primary sewing up.

The most common serious sequelae of war injuries to the jaw have been recurrent and secondary haemorrhages, inhalation pneumonia and gangrene of the lung, and me ̌ilastinitis.

Down to January, 1917, we had among 1,010 cases twenty-seven deaths, seven of these from pneumonia, 